\title{
Pasteurization of Shell Eggs using Radio Frequency Heating
}

David J. Geveke ${ }^{1 *}$, Andrew B. W. Bigley ${ }^{1}$, and Christopher D. Brunkhorst ${ }^{2}$

${ }^{1}$ Food Safety and Intervention Technologies Research Unit,

Eastern Regional Research Center, Agricultural Research Service,

U.S. Department of Agriculture, 600 East Mermaid Lane,

Wyndmoor, PA 19038, USA

${ }^{2}$ Princeton Plasma Physics Laboratory, Princeton University, MS08, C Site Engineering Wing 117, Princeton, NJ 08543, USA

*David J. Geveke

Tel: 215-233-6507; Fax: 215-233-6406; e-mail: david.geveke@ars.usda.gov.

${ }^{\dagger}$ Mention of trade names or commercial products in this publication is solely for the purpose of providing specific information and does not imply recommendation or endorsement by the U.S.

Department of Agriculture. USDA is an equal opportunity provider and employer. 


\begin{abstract}
The USDA-FSIS estimates that pasteurization of all shell eggs in the U.S. would reduce the annual number of illnesses by more than 110,000 . However, less than $3 \%$ of shell eggs are commercially pasteurized. One of the main reasons for this is that the commercial hot water process requires as much as 60 min to complete. In the present study, a radio frequency (RF) apparatus was constructed, and a two-step process was developed that uses RF energy and hot water, to pasteurize eggs in less than half the time. In order to select an appropriate RF generator, the impedance of shell eggs was measured in the frequency range of $10-70 \mathrm{MHz}$. The power density within the egg was modeled to prevent potential hotspots. Escherichia coli (ATCC 35218) was inoculated in the yolk to approximately $7.5 \log$ CFU/ml. The combination process first heated the egg in $35.0^{\circ} \mathrm{C}$ water for 3.5 min using $60 \mathrm{MHz} \mathrm{RF}$ energy. This resulted in the yolk being preferentially heated to $61^{\circ} \mathrm{C}$. Then, the egg was heated for an additional 20 min with $56.7^{\circ} \mathrm{C}$ water. This two-step process reduced the population of E. coli by $6.5 \log$. The total time for the process was $23.5 \mathrm{~min}$. By contrast, processing for $60 \mathrm{~min}$ was required to reduce the E. coli by $6.6 \log$ using just hot water. The novel RF pasteurization process presented in this study was considerably faster than the existing commercial process. This should lead to an increase in the percentage of eggs being pasteurized, as well as a reduction of foodborne illnesses.
\end{abstract}

\title{
Keywords
}

Radio frequency; dielectric heating; shell eggs; pasteurization; impedance; finite element modeling 


\section{Introduction}

Shell eggs and egg products were ranked the second riskiest food regulated by the FDA, and were linked to 352 outbreaks from 1990 to 2006 (Klein et al., 2009). Escherichia coli, including extraintestinal pathogenic E. coli (ExPEC), has been isolated from eggs (Englmaierova et al. 2014; Mitchell et al. 2015). The USDA-FSIS estimates that pasteurization of all shell eggs in the United States (i.e., reducing the bacterial population by $5 \log$ ) would decrease the annual number of illnesses by more than 110,000 (Schroeder et al., 2006).

Currently, only two companies in the U.S. pasteurize shell eggs. They both use hot water immersion whereby the eggs are submerged in water at an elevated temperature for approximately 60 min (Day, 2010). There are two reasons for the lengthy time required for the commercial hot water process. The first is the limiting temperature of the water. The foaming power of albumen begins to decline when momentarily subjected to a temperature of $57{ }^{\circ} \mathrm{C}$ (Cunningham, 1995). Van Lith et al. (1995) immersed shell eggs in hot water and determined that $57^{\circ} \mathrm{C}$ is the maximum water temperature that can be used without coagulating the albumen. Pathogenic bacteria are not quickly inactivated at $56.7^{\circ} \mathrm{C}$. The U.S. Department of Agriculture's required minimum holding times for pasteurizing liquid yolk are 6.2 and $3.5 \mathrm{~min}$ at 60.0 and 61.1 ${ }^{\circ} \mathrm{C}$, respectively (USDA, 1969). At a temperature of $56.7^{\circ} \mathrm{C}$, the pasteurization holding time is estimated to be 35 minutes (USDA 1969). Based on the results of Humphrey et al. (1990), who determined the $D$-values of Salmonella in egg yolk at 55 and $60{ }^{\circ} \mathrm{C}$, the $D$-value at $56.7^{\circ} \mathrm{C}$ is approximately $7.4 \mathrm{~min}$ (Geveke et al. 2016). The second reason for the protracted hot water process is that the heat must first be transferred from the water to the shell, and then, by conduction, from the shell to the heat-sensitive albumen, and finally to the yolk. The come-up time (i.e., the time required to raise the yolk temperature to $57^{\circ} \mathrm{C}$ ) is 20 min or longer (Cox et 
al., 1996; Geveke et al., 2016; Park and Cho, 2006; Stadelman et al., 1996). The lengthy hot water immersion process contributes to the cost of commercially pasteurized eggs. In some cases, adding more than $\$ 1$ to the price of a dozen eggs (Sinclair, 2012).

Alternative techniques for pasteurizing shell eggs have been researched, but only one of these has been commercialized. This process uses microwave energy and is practiced only in South Africa (Wiid, 2008). Microwave energy can penetrate into the shell egg and heat up the yolk faster than hot water. However, the penetration depth of microwaves (915 and $2450 \mathrm{MHz}$ ) in foods can be as low as $0.3 \mathrm{~cm}$ (Tang et al., 2004). This means that very little microwave energy may make it to the yolk. The patent, which forms the basis of the South African microwave process, indicates that the method takes approximately 30 to 40 min and results in a bacterial reduction of between 2 and $5 \log$ (Erasmus and Rossouw, 2008). In addition, the process causes a slight haziness of the albumen and a reduction in whipping ability (Wiid, 2008).

Penetration depth of electromagnetic energy is inversely dependent on the frequency. Thus, radio frequency (RF) energy, which ranges from 10 to $300 \mathrm{MHz}$ (Orfeuil, 1987), can have a penetration depth ten times greater than that of microwave energy (Tang et al., 2004). The deeper penetration of RF energy should heat the yolk better than microwave energy and prevent loss of albumen quality. The use of RF energy to pasteurize shell eggs is discussed very little in the literature. Hamid-Samimi et al. (2002) reveal the use of RF energy to rapidly pasteurize egg products. However, the majority of their patent deals with processing liquid egg products and scant information is given regarding shell eggs. More recently, Dev et al. (2012) modeled the heating of shell eggs in a parallel plate RF applicator. The modeling showed that heating would be highly nonuniform and may lead to the generation of hot spots in the albumen. The modeling also indicated that rotating the eggs would reduce the nonuniformity; however, these results were 
not experimentally validated. Kannan et al. (2013) heated eggs with a parallel plate RF applicator to $56^{\circ} \mathrm{C}$. Coagulation of the albumen was avoided, but only by prolonging the heat-up time to 45 min which approaches the time required for conventional hot water processing. In addition, no microbiological testing was performed.

RF energy, applied with a unique converged applicator, has been used to pasteurize apple cider and orange juice with minimal effects on quality (Geveke et al., 2007; Geveke and Brunkhorst, 2008). Research is needed to determine if shell eggs can be pasteurized using RF energy, applied in a more precise manner rather than by a simple parallel plate applicator. The present study developed a RF applicator that placed the egg in direct contact with curved electrodes. The equivalent circuit of the egg and electrodes is a series RC circuit. The resistance (R) is composed of the conductive albumen and yolk, while the capacitance (C) is due to the egg shell acting as a dielectric. Application of RF to the electrodes creates electric fields in both the resistive and capacitive portions of the egg. Due to the conductive nature of the albumen and yolk, power is dissipated ohmically. By closing the gap between the electrodes and the shell, the capacitance of the RC circuit is increased. Thus, a lower voltage at the electrodes is required to maintain the same degree of heating, and the potential for hotspots in minimized. Most commercial RF power systems operate at a source impedance of $50 \Omega$. For maximum power transfer, the load impedance should match the source impedance. The optimum frequency for impedance matching would be where the series impedance of the egg/electrode circuit would be closest to a value of $50+\mathrm{j} 0 \Omega$. The intention of using this RF applicator is to gently pasteurize shell eggs in less time than using the conventional hot water immersion method with the aim of increasing the percentage of eggs pasteurized in the U.S. and reducing foodborne illness. 
The major goals of this study were to: (1) design and assemble an apparatus to apply RF energy to a shell egg in a controlled fashion; and (2) develop a process for pasteurizing shell eggs using RF energy. To these ends, additional objectives included measuring the impedance of a shell egg and modeling the power density within the egg during RF processing.

\section{Materials and Methods}

Escherichia coli (ATCC 35218), a surrogate for Salmonella, was maintained on tryptic soy agar (TSA; Becton, Dickinson and Company, Franklin Lakes, NJ) at $4{ }^{\circ} \mathrm{C}$. The E. coli was cultured in tryptic soy broth (Becton, Dickinson and Company) with shaking at $37^{\circ} \mathrm{C}$ for $16-18$ h.

Shell eggs were obtained from a local commercial egg producer. Eggs were sorted to obtain eggs weighing 61 to $64 \mathrm{~g}$ each and were stored overnight at room temperature $\left(23{ }^{\circ} \mathrm{C}\right)$ prior to being inoculated.

The large ends of the eggs were first perforated by hand with an 18 gauge sterile needle (Becton, Dickinson and Company). Following shell perforation, eggs (with the large end up) were placed in an inoculation device (designed and assembled in-house) that precisely injected the E. coli inoculum into the geometric centers of the yolks. The device was comprised of a Hamilton, Gastight model 1725LT, luer tip, autoclavable, $250 \mu 1$ glass syringe (Hamilton Co., Reno, NV) and a 16 gauge, $3.8 \mathrm{~cm}$ needle (Beckton-Dickson) that were clamped to a low-speed, battery-powered actuator. The glass syringe was filled with the inoculum and centered over the hole in the large end of the egg. The actuator slowly pushed the tip of the needle through the hole to a depth of $3.2 \mathrm{~cm}$ and into the center of the yolk. Eggs were then slowly injected with $50 \mu 1$ of inoculum. This was followed by a 30 s delay to permit pressure equilibration within the egg to 
prevent inoculum leakage from the yolk. The actuator then slowly retracted the needle and the egg hole was sealed with a drop of fast-curing epoxy gel (1 Minute ${ }^{\mathrm{TM}}$ \#14277, ITW Devcon, Danvers, MA) and allowed to cure for at least $30 \mathrm{~min}$ before thermal treatments. The population of $E$. coli in the whole egg was measured at approximately $7.5 \log \mathrm{CFU} / \mathrm{ml}$ (positive control). Preliminary trials using a dye technique were done to confirm that cultures were inoculated into the geometric center of the yolks (Brackett et al., 2001). This technique consisted of injecting $50 \mu \mathrm{l}$ of dye into the egg followed by a standard hard-boiling procedure to demonstrate consistent placement of the dye near the center of the yolk with no discernible drift (as shown in Figure 1).

For treatment with RF, a unique apparatus was designed and assembled in-house. The apparatus comprised an electrode that was attached to the large end of the egg and another to the small end (Fig. 2). The electrodes consisted of copper mesh (woven wire cloth, wire diameter $0.028 \mathrm{~cm}$, open area $67.9 \%$, McMaster-Carr, Elmhurst, IL) that was held in place with a retaining ring of zinc plated steel (for $4.1 \mathrm{~cm}$ shaft diameter, McMaster-Carr). A mesh was selected because the wire structure provided excellent electrical conductivity. The spaces between the wires allowed heat to freely transfer from the shell outwards, thus preventing any localized hot spots directly below the shell in the albumen. A clamp, made of high-strength electrical insulating material (Ultem, McMaster-Carr), applied a slight force to the electrodes which resulted in good contact between the electrodes and the egg. The egg and RF apparatus electrodes were then submerged in $35^{\circ} \mathrm{C}$ deionized water by placing them in a 2.51 plastic water bath. The purpose of the water was to cool the egg shell and protect the albumen from overheating. Thus, the RF energy preferentially heated the yolk. 
The electrodes were connected via a coaxial cable to a RF power supply (Model CPS1000/60, Comdel, Gloucester, MA). The power supply produced up to $1 \mathrm{~kW}$ at an output resistance of $50 \Omega$ and a frequency of $60 \mathrm{MHz}$. This frequency was selected based on measurements made on a room temperature shell egg with a vector impedance analyzer (model TE3000, Trewmac Systems Pty Ltd., Scott Creek, South Australia, AU). The impedance was measured across the egg between the large and small ends using the RF treatment apparatus shown in Figure 2. Because the impedance results indicated $60 \mathrm{MHz}$ would provide a fairly good match, a $60 \mathrm{MHz}$ power supply was purchased. An impedance matching network was designed and assembled in-house and installed into the RF circuit to adjust the resistance to $50 \Omega$. This ensured maximum coupling of energy from the power supply to the egg. The power supply included meters that measured forward and reflected power. Because of excellent matching, the reflected power was never more than $5 \mathrm{~W}$. The net power (i.e., forward minus reflected) is reported throughout.

The experimental procedure consisted of two parts. In the first part, RF energy was applied to the shell egg. The RF power was applied in segments. Between these applications, the egg was manually rotated to improve the temperature uniformity, as discussed in the Results and Discussion section. The egg was rotated around the axis running from the large end to the small end. Each rotation step was completed in $10 \mathrm{~s}$. The RF power was reduced in the latter segments (from $50 \mathrm{~W}$ to $25 \mathrm{~W}$ ) to further prevent damaging the heat sensitive albumen. This was compensated for by increasing the treatment times (from $45 \mathrm{~s}$ to $60 \mathrm{~s}$ ). The step by step method was to apply $50 \mathrm{~W}$ to an egg for $45 \mathrm{~s}$, rotate the egg $180^{\circ}$ in $10 \mathrm{~s}$, apply an additional $50 \mathrm{~W}$ for $45 \mathrm{~s}$, rotate $90^{\circ}$ in $10 \mathrm{~s}$, apply $25 \mathrm{~W}$ for $60 \mathrm{~s}$, rotate $180^{\circ}$ in $10 \mathrm{~s}$, and finally apply an additional $25 \mathrm{~W}$ for $60 \mathrm{~s}$. 
In the second and final part of the experimental procedure, the egg was disconnected from the RF apparatus and placed in a circulating water bath (model Isotemp 3016S, Fisher Scientific, Pittsburgh, PA) at $56.7^{\circ} \mathrm{C}$ for $20 \mathrm{~min}$. The temperature of the water bath was measured with a type K thermocouple connected to a data logger (model HH309A, OMEGA Engineering, Stamford, CT).

In some instances, eggs were not processed with RF energy (eliminating the first part), but were only placed in the $56.7^{\circ} \mathrm{C}$ water bath for 20 or $60 \mathrm{~min}$. This was done to compare the antimicrobial efficacy of hot water immersion alone to that of the combined RF and hot water process.

Eggs were sampled by first aseptically cracking the contents into a stainless steel Waring Mini-Sample Blender Container (model MC2, Waring Products, Torrington, CT), and blending on medium speed with a Waring model LB10G variable speed blender for $1 \mathrm{~min}$. The contents were then serially diluted with sterile $0.1 \%$ peptone solution and plated onto Petrifilm Aerobic Count Plates (3M, St. Paul, MN). Plates were incubated at $37^{\circ} \mathrm{C}$ for $24 \mathrm{~h}$ before enumeration.

In order to determine the temperatures of the albumen and yolk following RF treatment, the contents of an egg were immediately placed in a Petri dish. Then, the temperatures of the albumen and yolk were measured with a type $\mathrm{K}$ thermocouple.

Each experiment was performed in triplicate with duplicate plating. The standard deviation was calculated using Microsoft Excel statistical analysis algorithms.

The anisotropic alternating current (AC) flow within a shell egg was modeled with the finite element analysis software QuickField ${ }^{\mathrm{TM}}$ (version 5.0, Tera Analysis Ltd, Svendborg, Denmark). The model provided the power density distribution, in $\mathrm{W} / \mathrm{m}^{3}$ at $100 \mathrm{~V}_{\mathrm{rms}}$ at $60 \mathrm{MHz}$, within the egg. The shell egg consisted of the following components: air sac, albumen, yolk, and shell. The 
proportions and geometry are inexact; however, the model does serve by showing the effect of the air sac and the difference in properties of the various egg components. The following electrical properties of the egg were used in this model: dielectric constant of albumen, yolk, and shell of 80, 60 and 3.5, respectively, as well as conductivity of albumen, yolk, and shell of 0.78 , 0.25, and 0.0 S/m, respectively (Dev et al., 2008; Ragni et al., 2007).

\section{Results and Discussion}

For comparison to the radio frequency pasteurization process, shell eggs were pasteurized using a hot water immersion method, which was representative of the commercial processes used in the United States. When inoculated shell eggs were immersed in a circulating water bath at $56.7^{\circ} \mathrm{C}$ for $20 \mathrm{~min}$, the reduction of $E$. coli was $1.8 \pm 0.3 \log \mathrm{CFU} / \mathrm{ml}$. When the water bath treatment was extended to $60 \mathrm{~min}$, the inactivation increased to $6.6 \pm 0.8 \log \mathrm{CFU} / \mathrm{ml}$. These inactivation results agree with those of others who have studied hot water processing of inoculated shell eggs. Immersing shell eggs in a $57^{\circ} \mathrm{C}$ circulating water bath for 25 min gave reductions in Salmonella Enteritidis (SE) of about $3 \log$ (Hou et al., 1996). The population of SE in shell eggs was reduced by greater than $5.8 \log$ after a 65 min treatment in a $57^{\circ} \mathrm{C}$ circulating water bath (Schuman et al., 1997) and by $4.5 \mathrm{log}$ after a 60 min treatment in a $56.7^{\circ} \mathrm{C}$ circulating water bath (Geveke et al., 2016). The maximum water temperature that will not affect the quality characteristics of the eggs is $57^{\circ} \mathrm{C}$ (Van Lith et al., 1995).

The application of radio frequency (RF) heating could substantially reduce the total time to pasteurize shell eggs. This is because, unlike hot water which only heats the shell, RF energy has the potential to immediately penetrate into the egg. Therefore, the authors designed and assembled an apparatus (shown in Figure 2) that applies RF energy directly to a shell egg. As not 
all frequencies may provide a good electrical match with the egg, impedance measurements were performed to determine which frequency range would be most suitable. The results are shown in Table 1, and are the first of their kind, as far as the authors know. The resistance at $60 \mathrm{MHz}$ was $53.6 \Omega$ and was the closest to $50 \Omega$ of all frequencies tested. Most RF generators prefer to be driven in to a $50 \Omega$ load. In addition, the reactance at this frequency was $3.9 \Omega$ which was one of the closest to $0 \Omega$ of all frequencies tested (Table 1). A reactance of $0 \Omega$ indicates an excellent match between the load (egg) and RF generator. Based on the impedance results, a $60 \mathrm{MHz}$ RF generator was used for the shell egg pasteurization experiments.

Table 1. Impedances of a shell egg, at various frequencies, at the contacts at the small and large ends of the egg.

\begin{tabular}{cc}
\hline Frequency, MHz & Impedance, $\Omega$ \\
\hline 10 & $40.7-\mathrm{j} 134$ \\
\hline 20 & $32.0-\mathrm{j} 62.8$ \\
\hline 30 & $34.1-\mathrm{j} 36.0$ \\
\hline 40 & $35.9-\mathrm{j} 18.1$ \\
\hline 50 & $42.1-\mathrm{j} 5.11$ \\
\hline 60 & $53.6+\mathrm{j} 3.92$ \\
\hline
\end{tabular}


The anisotropic AC flow within the egg was modeled to determine the power distribution within the egg as described in the Materials and Methods section. The power density is the product of conductivity times the square of the electric field strength. The RF current flow within the egg is nonuniform, due to the geometry of the egg and electrodes, and the difference in conductive properties of the various egg components. Figure 3 presents the model's results for an applied $100 \mathrm{~V}_{\text {rms }}$ at $60 \mathrm{MHz}$. The highest power densities within the egg are located directly below the shell in the vicinity of the electrodes at either ends of the egg. Furthermore, the power densities are much higher in the albumen than in the yolk. These areas of elevated power density led to hot spots and damage to the albumen near the electrodes when eggs were heated with RF energy in air. Therefore, the RF treatment chamber was bathed in circulating water at $35.0{ }^{\circ} \mathrm{C}$ to cool the shell and albumen. As an additional precaution to prevent the occurrence of hot spots, the egg was rotated around its long axis. This was done because both the eggs and the RF treatment chamber are not perfectly symmetrical. These asymmetries could lead to an additive effect; that is, more power could be applied along one side of the egg than the other. By maintaining the position of the RF chamber and rotating the egg, the odds of creating a hot spot are decreased. Visual observation of the egg contents indicated that the combination of applying cooling water and rotating the eggs eliminated damage to the albumen.

The goal of the present study was to develop a faster pasteurization method for shell eggs as an alternative to the conventional hot water method. Consequently, a two-step RF/hot water immersion process was developed. In the first step, a shell egg was placed in a custom-built RF 
treatment apparatus, as shown in Figure 2. The RF device was placed in a $35^{\circ} \mathrm{C}$ water bath and $60 \mathrm{MHz}$ RF was applied for 3.5 min using the method given in the Materials and Methods section (above). In the second step, the egg was removed from the RF applicator and placed in a $56.7^{\circ} \mathrm{C}$ water bath for 20 minutes. Following this two-step procedure, the population of E. coli was reduced by $6.5 \pm 0.1 \log \mathrm{CFU} / \mathrm{ml}$. The appearances of the albumen and yolk were good with no visible damage. Similar results have been obtained at slightly different combinations of cooling water temperature, RF power and duration than those used in this study (data not shown).

The maximum temperatures of the albumen and yolk were 50 and $61{ }^{\circ} \mathrm{C}$, respectively, after the 3.5 min RF treatment (at the end of the first step of the process). The maximum albumen temperature was well below $57^{\circ} \mathrm{C}$, the temperature at which the foaming power of albumen begins to rapidly decline (Cunningham, 1995). Furthermore, the maximum yolk temperature indicates that at least some part of the yolk was at a temperature where the pasteurization holding time is estimated to be only 3.7 min (USDA 1969). The duration of the entire process was 23.5 min and resulted in a reduction of $E$. coli of greater than $6.8 \mathrm{log}$. By comparison, the reduction of E. coli using just hot water for 60 min was $6.6 \mathrm{log}$.

Future research plans include developing a RF treatment apparatus that automatically rotates the shell egg without the need for manually doing so. This will facilitate commercialization of the RF process and may be accomplished by placing the egg on rollers, similar to those used for washing eggs, and perhaps changing the location of the electrodes. Furthermore, Salmonella in addition to $E$. coli will be inoculated into eggs and processed with the RF technology. Additionally, egg quality testing will be performed to determine the effect of RF pasteurization on functionality. 


\section{Conclusions}

A novel method to pasteurize shell eggs using RF energy was developed which substantially reduces the treatment time. Whereas the conventional pasteurization method, using only hot water, needs approximately 60 minutes to complete, the new combination method, using RF heating and hot water, requires only 23.5 minutes. Thus, the pasteurization time has been reduced by $60 \%$.

\section{Acknowledgements}

The authors thank Messrs. J. Charlton, E. Tilman, and N. Geveke for engineering support, Mr. O.J. Scullen for microbiological support, and Mr. J. Sites for photographing the crosssection of the egg (all of the USDA-ARS, Wyndmoor, PA). They also wish to thank Mr. E. Tilman for reviewing the manuscript. 


\section{References}

Brackett, R.E., Schuman, J.D., Ball, H.R., \& Scouten, A.J. (2001). Thermal inactivation kinetics of Salmonella spp. within intact eggs heated using humidity-controlled air. Journal of Food Protection, 64(7), 934-938.

Cox, J.P., Cox, R.W.D., \& Cox, J.M. (1996). Method for processing poultry shell eggs. US Patent 5589211.

Cunningham, F.E. (1995). Egg-product pasteurization. In W.J. Stadelman \& O.J. Cotterill (Eds.), Egg science and technology (4th ed., pp. 296 \& 302). Food Products Press, New York.

Day, J. (2010). Pasteurized eggs put to test. Chicago Tribune. Available at: http://articles.chicagotribune.com/2010-09-08/features/sc-food-0910-pasteurized-eggs20100908_1_regular-eggs-whites-proteins. Accessed December 15, 2015.

Dev, S.R.S., Raghavan, G.S.V., \& Gariépy, Y. (2008). Dielectric properties of egg components and microwave heating for in-shell pasteurization of eggs. Journal of Food Engineering, 86(2), 207-214.

Dev, S.R.S., Kannan, S., Gariépy, Y., \& Vijaya Raghavan, G.S. (2012). Optimization of radio frequency heating of in-shell eggs through finite element modeling and experimental trials. Progress In Electromagnetics Research B., 45, 203-222.

Englmaierova, M., Tumova, E., Charvatova, V., \& Skrivan, M. (2014). Effects of laying hens housing system on laying performance, egg quality characteristics, and egg microbial contamination. Czech Journal of Animal Science, 59(8), 345-352.

Erasmus, C., \& Rossouw, M.J. (2008). In-shell pasteurization of eggs. European Patent 1746898B1. 
Geveke, D.J., Gurtler, J.B., Jones, D.R., \& Bigley, A.B.W. (2016). Inactivation of Salmonella in shell eggs by hot water immersion and its effect on quality. Journal of Food Science, 81(3), M709-M714.

Geveke, D.J., Brunkhorst, C., \& Fan, X. (2007). Radio frequency electric fields processing of orange juice. Innovative Food Science \& Emerging Technologies, 8(4), 549-554.

Geveke, D.J. \& Brunkhorst, C. (2008). Radio frequency electric fields inactivation of Escherichia coli in apple cider. Journal of Food Engineering, 85(2), 215-221.

Hamid-Samimi, M., Swartzel, K.R., \& Ball Jr., H.R. (2002). Method for the pasteurization of egg products using radio waves. US Patent 6406727.

Hou, H., Singh, R.K., Muriana, P.M., \& Stadelman, W.J. (1996). Pasteurization of intact shell eggs. Food Microbiology, 13(2), 93-101.

Humphrey, T.J., Chapman, P.A., Rowe, B., \& Gilbert, R.J. (1990). A comparative study of the heat resistance of Salmonellas in homogenized whole egg, egg yolk or albumen. Epidemiology \& Infection, 104(2), 237-241.

Kannan, S., Dev, S.R.S., Gariépy, Y., \& Vijaya Raghavan, G.S. (2013). Effect of radiofrequency heating on the dielectric and physical properties of eggs. Progress In Electromagnetics Research B, 51, 201-220.

Klein, S., Witmer, J., Tian, A., \& Smith DeWaal, C. (2009). The ten riskiest foods regulated by the U.S. Food and Drug Administration. Available at: http://cspinet.org/new/pdf/cspi_top_10_fda.pdf. Accessed January 28, 2016.

Mitchell, N.M., Johnson, J.R., Johnston, B., Curtiss III, R., \& Mellata, M. (2015). Zoonotic potential of Escherichia coli isolates from retail chicken meat products and eggs. Applied and Environmental Microbiology, 81(3), 1177-1187. 
Orfeuil, M. (1987). Electric process heating. Battelle Press. Columbus, OH.

Park, J.-M. \& Cho, Y.-S. (2006). Method of pasteurizing chicken shell egg. US Patent 7052726.

Ragni, L., Al-Shami, A., Mikhaylenko, G., \& Tang, J. (2007). Dielectric characterization of hen eggs during storage. Journal of Food Engineering, 82(4), 450-459.

Schroeder, C.M., Latimer, H.K., Schlosser, W.D., Golden, N.J., Marks, H.M., Coleman, M.E., Hogue, A.T., Ebel, E.D., Quiring, N.M., Kadry, A.-R.M., \& Kause, J. (2006). Overview and summary of the food safety and inspection service risk assessment for Salmonella Enteritidis in shell eggs, October 2005. Foodborne Pathogens and Disease, 3(4), 403-412.

Schuman, J.D., Sheldon, B.W., Vandepopuliere, J.M., \& Ball Jr., H.R. (1997). Immersion heat treatments for inactivation of Salmonella Enteritidis with intact eggs. Journal Applied Microbiology, 83(4), 438-444.

Sinclair, A. (2012). Making cookie dough safer. Crain's Chicago Business. Available at: http://www.chicagobusiness.com/article/20120225/ISSUE01/302259975/making-cookiedough-safer. Accessed December 15, 2015.

Stadelman, W.J., Singh, R.K., Muriana, P.M., \& Hou, H. (1996). Pasteurization of eggs in the shell. Poultry Science, 75(9), 1122-1125.

Tang, J., Wang, Y., \& Chan, T.V. (2004). Radio-frequency heating in food processing. In G. Barbosa-Canovas, M. Tapia, \& M.P. Cano (Eds.), Novel food processing technologies (pp. 501-524). Marcel Dekker, New York.

USDA. (1969). Egg pasteurization manual. ARS pub. 74-48. US Department of Agriculture Agricultural Research Service. Albany, CA.

Van Lith, L.A.J.T., Putirulan, F.F., \& Mulder, R.W.A.W. (1995). Pasteurization of table eggs to eliminate Salmonellae. Archiv Fuer Gefluegelkunde, 59(2), 157-160. 
Wiid, N. (2008). Commercial news: shell egg pasteurization - the facts. Poultry Pluimvee Bulletin, (1), 30-32. 


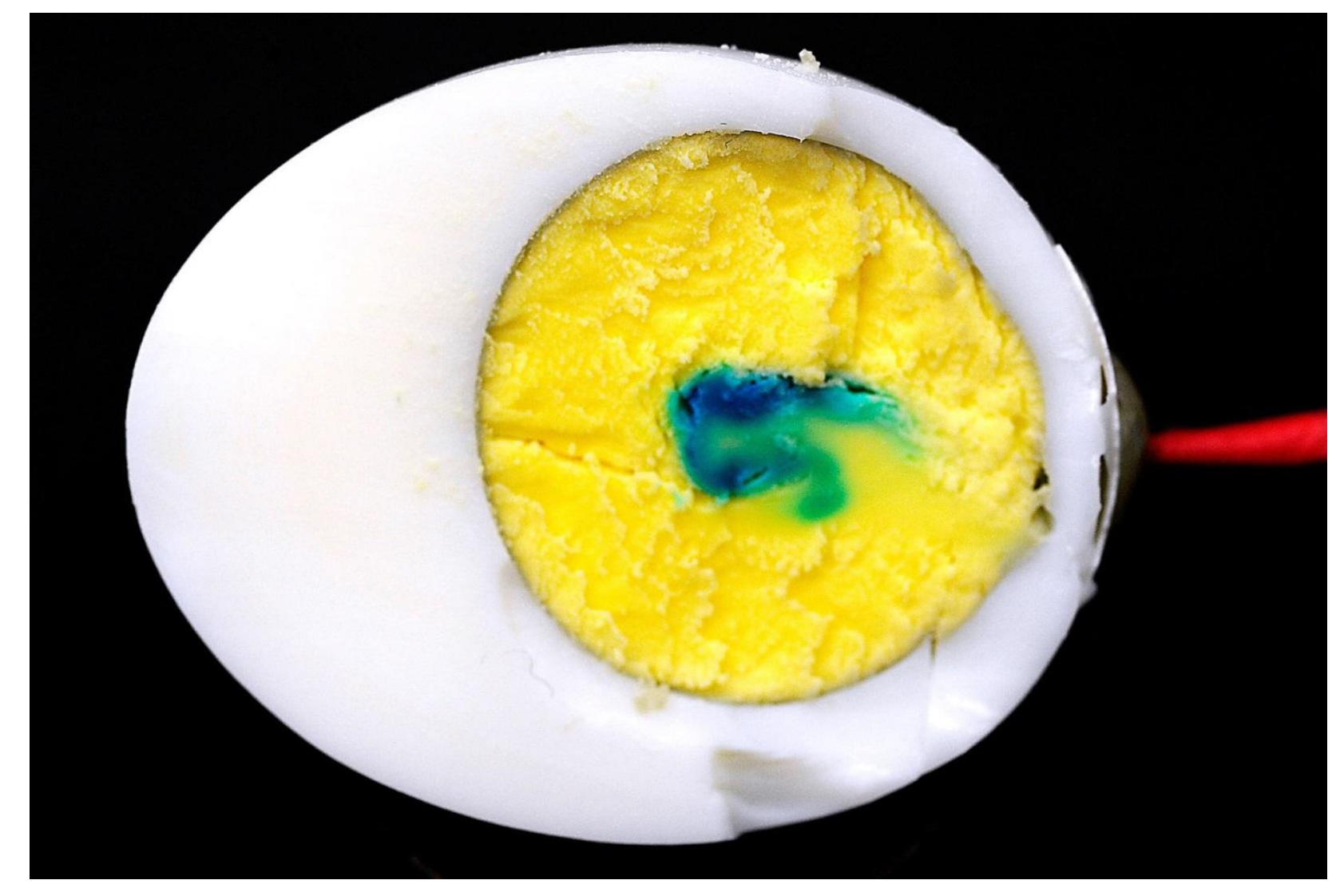

Fig. 1. Cross-section of a hard-boiled egg that had been injected with dye, to confirm the placement of inoculum at the center of the yolk. 


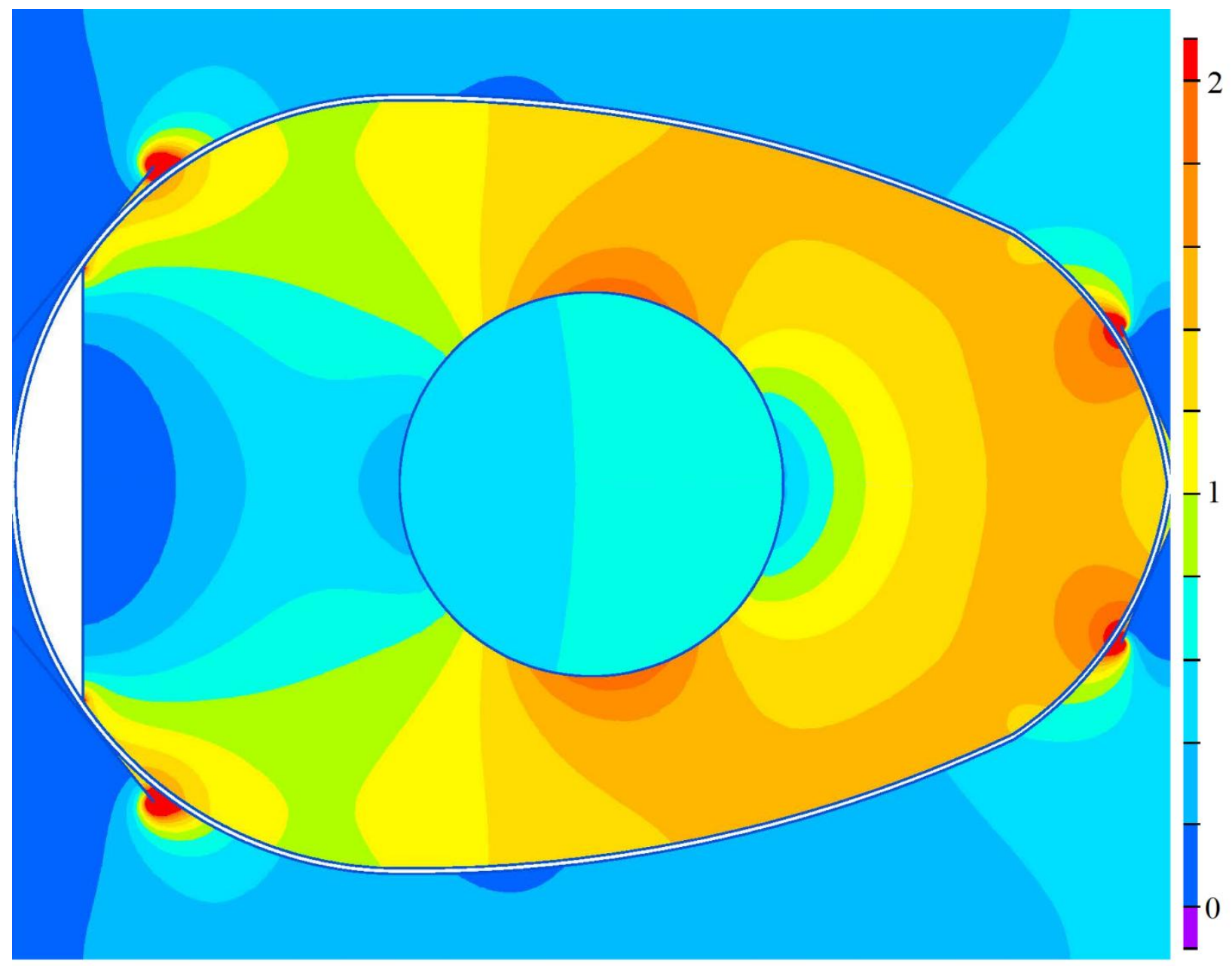

Figure 3. Modeled active power density ( $\left.\mathrm{Q}_{\text {active }}\right)$ within a shell egg, including albumen, yolk and air cell. The scale (at the right) has units of $\mathrm{W} / \mathrm{m}^{3}$. 


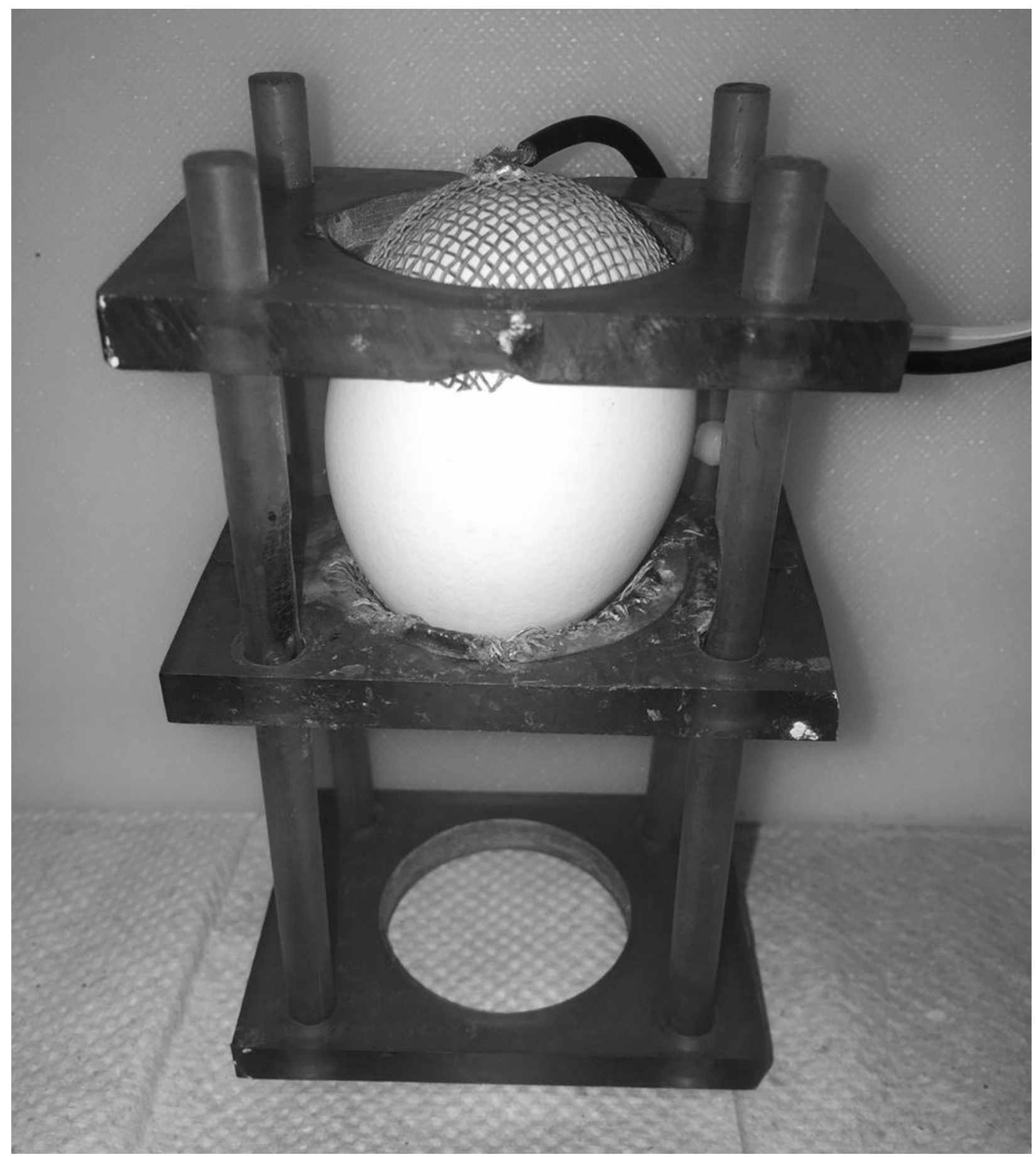

Fig. 2. RF treatment apparatus showing electrodes clamped to an egg. The electrodes

consisted of copper mesh. The clamping device was made of Ultem high-strength electrical insulating material. 